Outcome in young adults with ischemic stroke was studied in 287 consecutive patients ( 15 to 45 years) followed for 3 years by clinical examinations or telephone interviews at the University of Lille, Roger Salengro Hospital, France. (Leys D, Bandu L, Henon H et al. Neurology July (1 of 2) 2002;59:26-33). The annual mortality rate was $4.5 \%$ in the first year and $1.6 \%$ in the second and third year follow-up. The annual stroke recurrence rates were $1.4 \%$ and $1.0 \%$ in the first year and subsequent years, respectively. Epileptic seizures occurred in $6.6 \%$ of patients.

In an editorial, Kittner SJ (Stroke in the young, Coming of age. Neurology July (1 of 2) 2002;59:6-7) emphasizes the social toll of ischemic stroke described in the above studies of ischemic stroke in young adults: high incidence of divorce and job loss. He discusses the role of homocystinuria and B vitamin deficiency in the cause of vascular disease and stroke, and a genetic contribution to stroke risk, particularly in early-onset cases.

Report of the NIND\&S Workshop on perinatal and childhood stroke was published as a special article by Lynch JK et al. Pediatrics Jan 2002;109:109-123. See Ped Neur Briefs March 2002;16:21-22.

\title{
MINOR HEAD INJURY AS CAUSE OF STROKE
}

Stroke and acute hemiparesis developing within 15 minutes to 72 hours (mean 16.3 hours) after minor head injury is reported in 8 children, 2-7 years of age (mean $6.2 \mathrm{yrs}$ ), at Johann Wolfgang Goethe University, Frankfurt, Germany. CT or MRI showed cerebral infarctions affecting branches of the middle cerebral (3), anterior cerebral (1), posterior cerebral (1), and basilar (3) arteries, and involving the basal ganglia, internal capsule, and brain stem. Prothrombotic risk factors (increase in lipoprotein and factor V Leiden mutation) were present in 2 children. Outcome at a mean of 3.9 year follow-up, classified by the Glasgow scale, was a moderate disability in 4 , severe disability (2), non-disabling sequelae (1), and total recovery (1). Minor head injury may explain some cases of so called "idiopathic" strokes. (Kieslich M, Fiedler A, Heller C, Kreuz W, Jacobi G. Minor head injury as cause and co-factor in the aetiology of stroke in childhood: a report of eight cases. I Neurol Neurosurg Psychiatry July 2002;73:13-16). (Respond: Dr Matthias Kieslich, Department of Paediatrics, Paediatric Neurology, Johann Wolfgang Goethe University, Theodor-Stern-Kai 7, 60590 Frankfort/Main, Germany).

COMMENT. Stretching and shearing forces imposed by minor head injuries can lead to a traumatic endothelial intimal lesion of small intraparenchymal end arteries. This is followed by fibrin accumulation, leukocyte reaction and formation of a white thrombus that occludes the arterial lumen after a latency period. The minor trauma may be the only cause of stroke or a co-factor in etiology in cases having a prothrombotic or other known risk factor. A recent media publicized and alleged case of a child developing a cerebral hemorrhage or stroke following a ride on a roller coaster may represent an under-recognized example of minor head injury as a precursor of stroke in young children. Risk factors for hemorrhagic stroke in children include vascular malformation, malignancy, trauma, and coagulation disorders. 